\title{
Positive Attitude: A Guarantee for Success in Employment
}

\author{
Aiqing Meng \\ Dezhou University, Dezhou 253023, China \\ E-mail: mengaq1198@163.com
}

\begin{abstract}
Faced with the current severe employment situation, college students have passive psychology, which influences their employment. In order to have better employment, college students should have positive psychological quality.
\end{abstract}

Keywords: College students, Employment, Psychological quality

According to American scholar Napoleon Hill, the minor differences among people may lead to great differences. Here minor differences refer to those between positive and negative attitudes and great differences refer to those between success and failure.

Positive attitude helps to conquer difficulties, establish confidence and maintain plenty of fight while negative one will depress people, fill their heart with complaint or restrict and even strangle their potentials.

\section{Manifestations of Students' Negative Employment Psychology}

\subsection{Lacking in Confidence and Depending Excessively on Others}

Some students are always filled with anxiety about their employment. Even when faced with their ideal job, they may be depressed by the great number of applicants. Although they know it is quite necessary for them to promote themselves, they have no courage to step into the employing units. Some other ones depend excessively on their parents or friends and wait for them to negotiate with the employing units and therefore to determine their fates. There are still some students who may flush with shame and be at a loss about the interviewer's questioning when asked. All these problems are caused by their lack of confidence as well as a right and all-round knowledge about themselves.

\subsection{Self-humiliation and Self-containment}

Due to some reasons in physical condition and family background, some students are worried that others may look down upon them, hence suffering from self-denial and self-containment. For example, some feel ashamed about their inferior height or their origin from remote countryside; some are afraid of communicating with others due to their optical problems or homely appearance. Such self-abased psychology has severely influenced college graduates' employment.

\subsection{Hesitation}

No job is perfect in the world since every one has his advantages as well as disadvantages. When making two-way selections, some students tend to be over hesitant to make decisions, be filled with fears and misgivings, and be upset even after a decision has been made. Once someone praises them, they will be self-contented while they may be filled with regrets once someone criticizes them. Lacking a clear knowledge about themselves and attaching excessive importance to gain and loss, these graduates tend to lose a lot of good opportunities.

\subsection{Following the Crowd Blindly}

Following the crowd is a common phenomenon in our daily life, harassing some students in their employment sometimes. Some students only show their interest in those hot occupations and their desire for these occupations tends to be stronger with the increasing number of applicants for them; some others blindly copy others by choosing to go to big cities or developed areas. By confining themselves on a narrow road to find a job due to their lack of self-recognition and the right sense of employment according to their reality, these students lose a lot of employment opportunities.

\subsection{Pursuit for Stable and Relaxed Life}

In the current severe employment situation, some graduates have established some blocks on their way to employment by blindly pursuing steady and comfortable life instead of starting from their own reality. Here pursuing steady life means they tend to choose those secure jobs from the perspective of occupational stability 
due to the influence of traditional thoughts; pursing comfortable life means some students, regarding themselves as intellectuals with high social status, claim that they should have comfortable and easy jobs instead of hard ones. These students tend to be unemployed after graduation and therefore have to turn to their parents for living.

\subsection{Endless Complaining}

The era in which every graduate will be offered a job has passed although it was once popular in 1980s when talents were quite limited. It is described in a vivid way that nobody will say "please" to you first on the way to find a job. Instead, you have to knock hard at the door until someone comes to open it for you. Not understanding the truth, some graduates just complain about their misfortune and spend their time in depression instead of exerting their own subjective initiative to be adapted to the changes in situation and to enter the employment market on their own initiative.

\subsection{Overestimating Themselves and Reaching for What is beyond Their Grasp}

Some students claim that they are capable of any job and quite particular when choosing their jobs. For example, there is a "three high" principle in students' attitudes towards employment, including high starting point, high salary and high position. Some even have mental comparisons. In their opinion, since they are better than others, they should choose better jobs as well, hence a six-point requirement for their jobs, including better fame, well-known brand, high profit, easy job, short distance from their home and loose management. Obviously, they are pursuing easy and comfortable life and are afraid of enduring hardships. This kind of employment idea is obviously characterized by pursuing profit, enjoyment and fame. They will bump against the wall during their employment process inevitably. Actually these problems result from their lacking knowledge about the society as well as insufficient rational knowledge about themselves. With the current fierce competition, graduates are supposed to comply with the demands of social development, to proceed from the actual conditions, to keep up with the times, to establish the sense of self-improvement, self-independence and self-confidence, to face up to their weaknesses, to exert their advantages according to social demands and their conditions and to find their ideal occupations through two-way selection.

Currently, it is not exaggerating to describe college students' employment psychology as "turning pale with the every mention of employment". Of course, this phenomenon is attributed to current difficulty in employment, however, their loss of confidence plays an important role as well. It should be emphasized that the whole society is exerting great efforts to face up to the current international financial crisis, which may have direct effects on some people while subtle ones on others. What is really important doesn't lie in whether students can get jobs immediately but the significance of their positive attitudes with which we can face up to crisis, just as what Premier Wen Jiabao once said. Only with confidence will college graduates are fully prepared for employment and actively look for proper opportunities. Otherwise, their complaints will only exert negative influences on students themselves as well as the society.

\section{Establishing Positive Confidence in Employment}

An American scholar in potentiality success claims that nothing is of greater importance than the belief one holds when facing adverse circumstances or difficulties. It is positive attitudes that create life and negative ones consume life. Positive attitudes act as the starting point for success, offer sunshine, rain and dew for life and change people's soul into a soaring eagle, while negative ones are the source for failure, a chronic killer of life and confine people to certain shadow they set for themselves.

\subsection{Establishing Employment Objectives}

It is the first step as well as a critical one to establish employment objectives in order to maintain positive employment psychology. Two points should be paid attention to during the process: first is to have a right understanding of oneself, that is, to carefully and objectively analyze one's own interest, personality and ability, to confirm what to do, what he can do and how his competitiveness is. Second is to have a right knowledge about the current employment situation, that is, to consider the demands for one's major and ideal job and the intensity of future competition, how to make up for inconsistence if one's ideal job is inconsistent to his major, some specific requirements working units have for applicants and so on.

\subsection{Overcoming Self-abasement and Establishing Self-confidence}

Self-confidence is a positive evaluation for oneself, according to which a person should believe that he has what is required in a career and master the courage to participate in competition.

\subsection{Showing no Fear at Frustrations and Having Strong Psychological Endurance}

Strong psychological endurance capability, a critical part in the current society with fierce competition, will help 
people to resist against frustrations and keep enterprising spirits. Due to the commonness of failures in employment nowadays, it is obviously the manifestation of poor psychological endurance to feel annoyed, depressed or even self-abased. On the contrary, a real powerful man will ponder upon their failure and learn from that to pursue new opportunities in future.

\subsection{Strengthening Self-contingency}

Contingency means that college students should adjust their employment expectation and knowledge ability structure according to their actual condition in order to maintain the greatest adaptability to the demands of employment market. With the rapid development of our society, the categories and requirements of employment tend to vary at a higher pace. Perhaps a hot major at the time a student enters college becomes saturated when he graduates, hence causing great difficulties in finding a job. Therefore, it is an effective way to greatly enhance students' contingency in order to reduce their worries about employment, such as taking a minor major or learning as much knowledge and technique as possible required by their ideal jobs.

\subsection{Knowing Oneself as Well as the Enemy}

Knowing oneself means having a real evaluation on oneself, having right knowledge about oneself, realizing one's own strengths and weaknesses objectively and correctly as well as learning about one's own personality, interest and specialties. Knowing the enemy means learning about the social employment environment as well as working units, correctly understanding the current employment situation and learning what types of college graduates are needed by the society. To sum up, students are expected to know what they want to do and what they can do.

\section{References}

Feng, Lan. (2004). Psychological Analysis and Countermeasures on College Students' Difficulty in Employment. Journal of Southwest University for Nationalities (arts), (1): pp 408-410

Xiong, Ping. (2006). Career Plan. Central South University Press, April. 